\title{
THE SALINE AQUATIC SYSTEMS AS 'NATURAL RESERVOIRS' FOR MICROORGANISMS WITH CURRENT AND POTENTIAL APPLICATIONS
}

\author{
Doriana M. BUDA ${ }^{1 \S}$, Paul A. BULZU ${ }^{1 \S}$, Adorján CRISTEA ${ }^{1}$ 的 \\ Horia L. BANCIU ${ }^{1,2}$
}

DOI: 10.24193/AWC2019_42

\begin{abstract}
Saline aquatic systems include inland and marine-derived lakes, solar salterns, or temporary inland saline ponds. Despite their high salinity, these ecosystems are inhabited by diverse microbial communities driving full biogeochemical cycling of main elements. To date, numerous salt-loving (or 'halophilic') environmental strains with metabolic traits of applicative interest belonging to all Domains of Life (Bacteria, Archaea, Eukarya) have been isolated from saline aquatic systems. The aim of the present work is to briefly review some of the most relevant achievements in the bioprospecting of saline aquatic systems for compounds and metabolic capabilities with potential uses in the environmental, industrial, and food biotechnologies. Additionally, the successful stories of current commercial exploitations of a few halotolerant (e.g., the bacterium Halomonas elongata), halophilic (e.g., the green algae Dunaliella sp.), and haloalkaliphilic microbes (e.g., the sulfur-oxidizing bacteria of genus Thioalkalivibrio sp.) are overviewed.
\end{abstract}

Keywords: biotechnology, Dunaliella, Halomonas, haloarchaea, halophiles, saline aquatic systems

\section{INTRODUCTION}

The saline aquatic systems encompass diverse inland and marine-derived bodies of water that share high salinity conditions (i.e., higher than that of the seawater, 3.5\% w/v) (Oren, 1998; Javor, 2012).

The relatively widespread occurrence of saline lakes fuelled the interest for the systematic investigation of their hydro-geochemistry and biodiversity (Oren, 2015) equally aiming at the understanding of their exploitation potential (e.g., for industrial salt recovery, aquaculture, or recreational purposes) and their ecological relevance (Williams, 1998; Javor, 2012). Although multi-valent importance

\footnotetext{
${ }^{1}$ Department of Molecular Biology and Biotechnology, Faculty of Biology and Geology, "Babeș-Bolyai" University, 5-7 Clinicilor Str., RO-400006, Cluj-Napoca, Romania. cristea.adorjan@gmail.com

2 Center for Systems Biology, Biodiversity, and Bioresources, "Babeș-Bolyai" University, 5-7 Clinicilor Str., RO-400006, Cluj-Napoca, Romania.

$\S$ These authors contributed equally to this work.
} 
(economic, cultural, aesthetic, recreational, ecological, scientific, etc.) is recognized for these peculiar ecosystems, dramatic threats posed by prospective climate changes (i.e., progressive salinization and subsequent drying) are foreseen in the absence of conservation strategies (Wurtsbaugh et al., 2017).

There was a traditional consensus that habitats with high salinity values are rather physico-chemically restrictive to life through their simultaneous low water activity (Grant, 2004) and high osmotic pressure (Oren, 2013). In addition to these apparently limiting factors, salt lakes with multiple-extreme conditions (e.g., high light irradiance, high $\mathrm{pH}$ and temperature values) are known in arid or semiarid areas in Northern America, Eastern Africa, and Central Siberia (Javor, 2012; Sorokin et al., 2015). In spite of these extreme conditions, highly diverse and abundant microbial communities comprising representatives of all Domains of Life (Bacteria, Archaea, and Eukarya) thrive within most of the saline habitats (Oren, 2008; Oren, 2015).

Therefore, such apparently extreme habitats and their surroundings might be regarded as 'natural reservoirs' or hotspots of biodiversity. It was recently hypothesized that, at least for some halophilic species, the adaptive (genetic and metabolic) fitness would support even larger salinities (i.e., equivalent to more extreme water scarcity) if salt-solubility threshold would be higher (Lee et al., 2018).

In an attempt to fill in the picture of the saline aquatic ecosystems as highly valuable and multi-faceted habitats, here we aim to briefly review some of the main achievements in the prospecting of saline aquatic systems for microorganisms with metabolic attributes useful in industrial, environmental or food biotechnologies. In addition, a few examples of current applications of halophiles will be overviewed.

\section{CURRENT AND POTENTIAL USES OF HALOTOLERANT AND HALOPHILIC BACTERIA AND EUKARYA}

A burning question nowadays challenges every biotechnological process which ends up with production of biomolecules: which is the quickest and easiest way to reduce production costs, energy and input material in order to obtain a costeffective production of a certain biomolecule? (Chen and Jang, 2018). Over the past years various research groups came up with answers and ideas, creating a so called "next generation industrial biotechnology" - NGIB. Candidates for NGIB can be various groups of microbes, particularly those living in extreme environmental conditions like halophiles (Chen and Jang, 2018).

Halophiles represent a very unique and important source of NGIB candidates, since these living organisms harbour growth adaptations in hypersaline conditions (Chen and Jang, 2018). Careful investigation of worldwide located hypersaline sites (e.g., salt lakes, solar salterns, evaporation ponds, saline mashes) and frequent isolation of moderate halophilic or halotolerant bacterial strains resulted in the identification of numerous species which later proved to show applicative potential 
(Setati, 2010; Yin et al., 2015). Members of Halomonas sp., (Gammaproteobacteria Class) are notorious for their ability to synthesize biopolymers such as the intracellular polyhydroxybutyrate (PHB). PHB is a biodegradable, thermostable and biocompatible natural polymer also known as 'green plastic' (Cervantes-Uc et al., 2014; Chen et al., 2017). For example, Halomonas nitroreducens isolated from the surface water of Las Coloradas solar salt pond (Mexico), was able to produce up to $33 \mathrm{w} \%$ PHB (Cervantes-Uc et al., 2014). Halomonas bluephagenesis was originally isolated from the hypersaline Aydingol Lake (Xinjiang Province, China) and showed high PHB production (61 w\% PHB) during growth in a non-sterile bioreactor (Chen et al., 2017). Genetically transformed $H$. bluephagenesis was capable of enhanced PHB production in large scale bioreactors (Chen and Jang, 2018).

Recently, Cristea et al., (2018) showed that a Halomonas elongata strain, isolated from a Romanian salt lake, was able to produce $40 \mathrm{w} \%$ PHB under high salt concentration $(10 \% \mathrm{w} / \mathrm{v} \mathrm{NaCl})$ using $\mathrm{D}$-glucose as sole carbon source. Similarly, a halotolerant Bacillus megaterium (Bacilli Class) isolate retrieved from a mud sample collected from the hypersaline Uyuni Lake (Bolivia), synthesized up to 39 w\% PHB (Salgaonkar et al., 2013).

Besides biopolymer production, the halotolerant $H$. elongata was reported as an important ectoine producer. Ectoine represents a class of compatible solutes with the key role of maintaining osmotic balance in hyperosmotic conditions (Sauer and Galinski, 1998). Isolated from a salt lake located in Wadi El Natrun (Egypt), the strain produce ectoine as compatible solute (Sauer and Galinski, 1998). Currently, the bitop AG company (Dortmund, Germany) use H. elongata to manufacture commercial ectoine $\left(\right.$ Ectoin $\left.^{\circledR}\right)$ as component of anti-aging and skin-care cosmetics.

Salt-stable enzymes with potential uses in food or detergent industry were characterized from Halomonas meridiani isolated from the saline Organic Lake (Vestfold Hills, Antarctica). This strain was able to synthesize salt-tolerant $\alpha$ amylases (Coronado et al., 2000). Similarly, Halomonas sp., strain PS47, isolated from Baad-Gudeangadi salt marsh (India) was capable to produce halostable cellulases (Shivanand et al., 2013).

A succesful example of environmental biotechnology using halophilic bacteria is the desulfurisation of industrial effluents by two-stage THIOPAQ ${ }^{\circledR}$ process. The gaseous, toxic hydrogen sulfide $\left(\mathrm{H}_{2} \mathrm{~S}\right)$ is first chemically solubilized at alkaline $\mathrm{pH}$ to its ionic form $\left(\mathrm{HS}^{-}\right)$. The sulfide is then converted to non-toxic elemental sulfur $\left(\mathrm{S}^{\circ}\right)$ in a bioreactor by chemolithoautotrophic haloalkaliphilic sulfur-oxidizing Thioalkalivibrio spp. (Gammaproteobacteria Class) that were isolated from soda lakes worldwide (Banciu et al., 2004; Sorokin et al., 2008; Muyzer et al., 2011).

A particular halophilic eukaryotic organism found in various saline aquatic ecosystems is the unicellular green algae Dunaliela salina, which produces glycerol as osmoregulator and $\beta$-carotene as light protectant (Ben-Amotz and Avron, 1981). The industrial $\beta$-carotene production from $D$. salina is presently achieved by Monzón Biotech company (Barcelona, Spain). The commercial $\beta$ carotene is further used in food industry, agriculture and cosmetics. 


\section{APLICATIVE POTENTIAL OF HALOPHILIC ARCHAEA}

Representatives of Archaea domain with strict requirement for high-salt concentration (obligately halophiles) are mainly found within the Halobacteria and Methanonatronarchaeia classes, Methanosarcinales order, and the candidate [Nanohaloarchaea] class, all assigned to Euryarchaeota Phylum (Andrei et al., 2012; Sorokin et al., 2018). The saline aquatic systems sharing oxic, highly-saline and photic conditions were sources for the isolation of many Halobacteria (or 'haloarchaea') species, some with properties of applicative interest: Halobacterium salinarum, numerous Haloferax spp., and Halorubrum spp. (Oren, 2014).

The aerobic heterotrophic haloarchaea are easy to cultivate and show versatile ability to degrade and synthesize a variety of organic compounds with interesting properties. For example, many haloarchaeal isolates retrieved from saline aquatic systems were demonstrated to synthesize biopolymers such as exopolysaccharides (EPS) or polyhydroxyalkanoates (PHAs). These products could be used as biodegradable materials in agriculture, medicine, green plastics or cosmetics industry (Poli et al., 2011). The fast-growing haloarchaeon Haloferax mediterranei isolated from a solar saltern near Alicante, Spain (Rodriguez-Valera et al., 1983) was evidenced for the production of both EPS (Antón et al., 1988) and PHA (Lillo and Rodriguez-Valera, 1990). This species was shown to accumulate poly- $\beta$ hydroxybutyrate as a storage polymer up to $38 \%$ of its dry weight under hypersaline and phosphate-limiting conditions and on cheap carbon sources (Fernandez-Castillo et al., 1986; Chen et al., 2006).

The bioremediation of polluted saline natural or wastewaters could be potentially attained by the exploitation of haloarchaeal strains (e.g., Haloferax spp.) based on their cumulative capacity to withstand high salinity and degrade or convert compounds such as nitrites (Martínez-Espinosa et al., 2007), aromatic hydrocarbons (Bonfá et al., 2011), xenobiotics (Ding and Lai, 2010) or heavy metals (Al-Mailem et al., 2018; see review of Voica et al., 2016) to less toxic forms.

The haloarchaeal adaptation to high salinity might be advantageous for their use in industrial processes that require elevated salt concentrations such as food preparation technologies like salty fermentations (e.g., fish sauce production) (Akolkar et al., 2010; see reviews of Oren, 2010; Singh and Singh, 2017). As several studies showed, archaeal species such as Natrinema gari and Halococcus thailandensis are the dominant organisms in salty, fermented foods (Namwong et al., 2007; Tapingkae et al., 2008).

Unique haloarchaeal metabolites have been described, including enzymes that are functional at high salt concentrations, and, in some cases, at extreme $\mathrm{pH}$ and temperature values. For instance, the extracellular $\alpha$-amylase synthesized by Halorubrum xinjiangense (isolated from Urmia Lake, Iran) with optimal activity at 4 $\mathrm{M} \mathrm{NaCl}, \mathrm{pH} 8.5$ and $70^{\circ} \mathrm{C}$, remains stable in the presence of a wide range of organic solvents and detergents, and therefore constitutes a potential industrial biocatalyst for various fields such as paper, textiles and pharmaceuticals production (Moshfegh et al., 2013; Kumar et al., 2016). Even so, to the best of our knowledge, no enzyme purified from halophilic archaeal strains has been used in industrial applications to this date, 
presumably because their bacterial correspondents are easier to handle, and do not lose their functionality at low salt concentrations (Oren, 2010).

A typical haloarchaeal components is the membrane-bound protein bacteriorhodopsin (BR). This light-dependent ion pump is probably the most acknowledged archaeal cell component acting as an alternative source for transmembrane proton motive force during low-oxygen and high-irradiance conditions. Haloarchaeal BR is currently manufactured by several commercial companies (e.g., Halotek Biomaterials, Sigma-Aldrich) to be used as high temperature, light or ionicstrength resistant biomaterial in bioelectronics, organic solar cells or as retinal analogue in nanomedicine (Wagner et al., 2013; see review of Ashwini et al., 2017).

A few haloarchaeal species (e.g., Halobacterium salinarum, Haloferax mediterranei) produce proteinaceous gas vesicles as part of their vertical migration mechanism (Pfeifer, 2015). A number of possible applications for gas-vesicle proteins (Gvp) were proposed including their use as contrast agents in medical diagnostics (ultrasound and magnetic resonance imaging). Moreover, GvpC fusion proteins were constructed, with potential use in antigen display or vaccine delivery (Cai et al., 2012; see review of Pfeifer, 2015).

\section{CONCLUSIONS}

Potentially useful features inherent in halophilic and halotolerant Bacteria and Eukarya make them feasible in a range of biotechnological applications. Even with yet limited current applications, their use in biotechnologies seems advantageous as they yield significant biomass during growth under high salinity which requires less sterilization. To date, no industrial-scale applications are known for haloarchaea in spite of their large repertoire of metabolic traits with potential uses in human economy.

Further efforts are needed to surpass technical and biological challenges of large-scale cultivation of bacterial and haloarchaeal strains to obtain significant biomass under high salinity conditions. Salts are chemically-aggressive compounds and therefore, while mitigating the corrosion risks by the decrease of salinity, some biochemical pathways of interest might be slowed or inactivated. Nevertheless, the innovations in genetic engineering will aid in establishing new strategies for enhanced halophilic bioconversions. In addition, the advent of 'next-generation' molecular techniques such as massive parallel sequencing of environmental DNA retrieved from various habitats opens perspective for discovery of novel genes or metabolic pathways of applicative interest.

\section{ACKNOWLEDGEMENTS}

The completion of this work was supported by grant of the Romanian National Authority for Scientific Research, CNCS - UEFISCDI, project number PN-III-P4ID-PCE-2016-0303. 


\section{REFERENCES}

1. Akolkar A.V., Durai D., Desai A.J. (2010), Halobacterium sp. SP1 (1) as a starter culture for accelerating fish sauce fermentation. J Appl Microbiol, 109, 44-53.

2. Al-Mailem D.M., Eliyas M., Radwan S.S. (2018), Ferric sulfate and proline enhance heavy-metal tolerance of halophilic/halotolerant soil microorganisms and their bioremediation potential for spilled-oil under multiple stresses. Front Microbiol 9, 394.

3. Andrei A.-Ş., Banciu H.L., Oren A. (2012), Living with salt: metabolic and phylogenetic diversity of archaea inhabiting saline ecosystems. FEMS Microbiol Lett 330(1), 1-9.

4. Antón J., Meseguer I., Rodriguez-Valera F. (1988), Production of an extracellular polysaccharide by Haloferax mediterranei. Appl Environ Microbiol 54(10), 23812386.

5. Ashwini R., Vijayanand S., Hemapriya J. (2017), Photonic potential of haloarchaeal pigment bacteriorhodopsin for future electronics: A review. Curr Microbiol 74(8), 996-1002.

6. Banciu H., Kleerebezem R., Muyzer G., Kuenen J. G., Sorokin, D. Y. (2004), Application of haloalkaliphilic sulfur-oxidizing bacteria for the removal of $\mathrm{H}_{2} \mathrm{~S}$ from gas streams, in book European Symposium on Environmental Biotechnology, ESEB 2004, Proceedings, Oostende, Belgium (pp. 345-348), Taylor and Francis Group. London, England.

7. Ben-Amotz A, Avron M. (1990), The biotechnology of cultivating the halotolerant algae Dunaliella for industrial products. Trends Biotechnol 8,121-126.

8. Bonfá M. R., Grossman M. J., Mellado E., Durrant L. R. (2011), Biodegradation of aromatic hydrocarbons by haloarchaea and their use for the reduction of the chemical oxygen demand of hypersaline petroleum produced water. Chemosphere 84(11), 1671-1676.

9. Cai L., Zhao D., Hou J., Wu J., Cai S., Dassarma P., Xiang H. (2012), Cellular and organellar membrane-associated proteins in haloarchaea: perspectives on the physiological significance and biotechnological applications. Sci China Life Sci 55(5), 404-414.

10. Cervantes-Uc J. M., Catzin J., Vargas I., Herrera-Kao W., Moguel F., Ramirez E., Rincón-Arriaga S., Lizama-Uc G. (2014), Biosynthesis and characterization of polyhydroxyalkanoates produced by an extreme halophilic bacterium, Halomonas nitroreducens, isolated from hypersaline ponds. J Appl Microbiol 117, 1056-1065.

11. Chen C.W., Don T.M., Yen H.F. (2006), Enzymatic extruded starch as a carbon source for the production of poly (3-hydroxybutyrate-co-3-hydroxyvalerate) by Haloferax mediterranei. Process Biochem 41(11), 2289-2296.

12. Chen G.Q., Jiang X.R. (2018), Next generation industrial biotechnology based on extremophilic bacteria. Curr Opin Biotech 50, 94-100.

13. Chen X., Yin J., Ye J., Zhang H., Che X., Ma Y., Li M., Wu L. P., Chen G. Q. (2017), Engineering Halomonas bluephagenesis TD01 for non-sterile production of poly (3-hydroxybutyrate-co-4-hydroxybutyrate). Biores Technol 244, 534-541.

14. Coronado M.J., Vargas C., Hofemeister J., Ventosa A., Nieto J.J. (2000), Production and biochemical characterization of an $\alpha$-amylase from the moderate halophile Halomonas meridiana. FEMS Microbiol Lett 183(1), 67-71.

15. Cristea A., Baricz A., Leopold N., Floare C. G., Borodi G., Kacso I., Tripon S., Bulzu P.A., Andrei A.-Ș., Cadar O., Levei, E.A., Banciu H.L. (2018), 
Polyhydroxybutyrate production by an extremely halotolerant Halomonas elongata strain isolated from the hypersaline meromictic Fără Fund Lake (Transylvanian Basin, Romania). J Appl Microbiol 125(5), 1343-1357.

16. Ding J.Y., Lai M.C. (2010), The biotechnological potential of the extreme halophilic archaea Haloterrigena sp. $\mathrm{H13}$ in xenobiotic metabolism using a comparative genomics approach. Environ Technol 31(8-9), 905-914.

17. Fernandez-Castillo R, Rodriguez-Valera F, Gonzalez-Ramos J, Ruiz Berraquero F. (1986), Accumulation of poly(beta-hydroxybutyrate) by halobacteria. Appl Environ Microbiol 51, 214-216.

18. Grant W. D. (2004), Life at low water activity. Philos Trans R Soc Lond B Biol Sci, 359(1448), 1249-1267.

19. Javor B.J. (2012), Hypersaline environments: microbiology and biogeochemistry, Springer Science \& Business Media.

20. Kumar S., Grewal J., Sadaf A., Hemamalini R., Khare S. K. (2016), Halophiles as a source of polyextremophilic $\alpha$-amylase for industrial applications. AIMS Microbiol 2(1), 1-26.

21. Lee C.J., McMullan P.E., O’Kane C.J., Stevenson A., Santos I.C., Roy C., Ghosh W., Mancinelli R.L., Mormile M.R., McMullan G, Banciu H.L., Fares M.A., Benison K.C., Oren A., Dyall-Smith, M.L., Hallsworth, J.E. (2018), NaCl-saturated brines are thermodynamically moderate, rather than extreme, microbial habitats. FEMS Microbiol Rev 42(5), 672-693.

22. Lillo J. G., Rodriguez-Valera, F. (1990), Effects of culture conditions on poly ( $\beta$ hydroxybutyric acid) production by Haloferax mediterranei. Appl Environ Microbiol 56(8), 2517-2521.

23. Martínez-Espinosa R.M., Zafrilla B., Camacho M., Bonete M.J. (2007), Nitrate and nitrite removal from salted water by Haloferax mediterranei. Biocatal Biotransformation 25(2-4), 295-300.

24. Moshfegh M., Shahverdi A.R., Zarrini G., Faramarzi, M.A. (2013), Biochemical characterization of an extracellular polyextremophilic $\alpha$-amylase from the halophilic archaeon Halorubrum xinjiangense. Extremophiles 17(4), 677-687.

25. Namwong S., Tanasupawat S., Visessanguan W., Kudo T., Itoh T. (2007), Halococcus thailandensis sp. nov., from fish sauce in Thailand. Int J Syst Evol Microbiol 57(10), 2199-2203.

26. Oren A. (1998), Microbiology and biogeochemistry of hypersaline environments (Vol. 5), CRC Press.

27. Oren A. (2008), Microbial life at high salt concentrations: phylogenetic and metabolic diversity. Saline Syst 4(1), 2.

28. Oren A. (2010), Industrial and environmental applications of halophilic microorganisms, Environ Technol 31(8-9), 825-834.

29. Oren A. (2013), Life at high salt concentrations, in book The Prokaryotes: Prokaryotic Communities and Ecophysiology (pp. 421-440), Springer. Berlin, Heidelberg.

30. Oren A. (2015), Halophilic microbial communities and their environments. Curr Opin Biotechnol 33, 119-124.

31. Oren, A. (2014), The Family Halobacteriaceae. In book The Prokaryotes: Other Major Lineages of Bacteria and The Archaea (pp. 41-121), Springer. Berlin, Heidelberg.

32. Pfeifer F. (2015), Haloarchaea and the formation of gas vesicles. Life 5(1), 385402. 
33. Poli, A., Di Donato P., Abbamondi G. R., Nicolaus B. (2011), Synthesis, production, and biotechnological applications of exopolysaccharides and polyhydroxyalkanoates by Archaea. Archaea, 2011.

34. Rodriguez-Valera F., Juez G., Kushner D.J. (1983), Halobacterium mediterranei spec, nov., a new carbohydrate-utilizing extreme halophile. Syst Appl Microbiol 4(3), 369-381.

35. Salgaonkar B.B., Mani K., Braganca J.M. (2013), Characterization of polyhydroxyalkanoates accumulated by a moderately halophilic salt pan isolate Bacillus megaterium strain H16. J Appl Microbiol 114, 1347-1356.

36. Sauer T., Galinski E.A. (1998), Bacterial milking: a novel bioprocess for production of compatible solutes. Biotechnol Bioeng 57, 306-13.

37. Setati M.E. (2010), Diversity and industrial potential of hydrolase-producing halophilic/halotolerant eubacteria. Afr J Biotechnol 9, 1555-1560.

38. Singh A., Singh A.K. (2017), Haloarchaea: worth exploring for their biotechnological potential. Biotechnol Lett 39(12), 1793-1800.

39. Shivanand P., Mugeraya G., Kumar A. (2013), Utilization of renewable agricultural residues for the production of extracellular halostable cellulase from newly isolated Halomonas sp. strain PS47. Ann Microbiol 63(4), 1257-1263.

40. Sorokin D.Y., Banciu H.L., Muyzer G. (2015), Functional microbiology of soda lakes. Curr Opin Microbiol 25, 88-96.

41. Sorokin D.Y., Merkel A.Y., Abbas B., Makarova K.S., Rijpstra W.I.C., Koenen M., Sinninghe Damste J.S., Galinski E.A., Koonin E.V., van Loosdrecht M.C. (2018), Methanonatronarchaeum thermophilum gen. nov., sp. nov. and 'Candidatus Methanohalarchaeum thermophilum', extremely halo (natrono) philic methylreducing methanogens from hypersaline lakes comprising a new euryarchaeal class Methanonatronarchaeia class nov. Int J Syst Evol Microbiol 68, 2199-2208.

42. Sorokin D.Y., Van Den Bosch P.L.F., Abbas B., Janssen A.J.H., Muyzer G. (2008), Microbiological analysis of the population of extremely haloalkaliphilic sulfuroxidizing bacteria dominating in lab-scale sulfide-removing bioreactors. Appl Microbiol Biotechnol 80(6), 965-975.

43. Tapingkae W., Tanasupawat S., Itoh T., Parkin K. L., Benjakul S., Visessanguan W., Valyasevi R. (2008), Natrinema gari sp. nov., a halophilic archaeon isolated from fish sauce in Thailand. Int J Syst Evol Microbiol 58(10), 2378-2383.

44. Voica D.M., Bartha L., Banciu H.L., Oren A. (2016), Heavy metal resistance in halophilic Bacteria and Archaea. FEMS Microbiol Lett, 363(14), fnw146.

45. Wagner N.L., Greco J.A., Ranaghan M.J., Birge R.R. (2013), Directed evolution of bacteriorhodopsin for applications in bioelectronics. J R Soc Interface 10(84), 20130197.

46. Williams W.D. (1998), Salinity as a determinant of the structure of biological communities in salt lakes. Hydrobiologia 381(1-3), 191-201.

47. Wurtsbaugh W.A., Miller C., Null S.E., DeRose R.J., Wilcock P., Hahnenberger M., Howe F., Moore J. (2017), Decline of the world's saline lakes. Nat Geosci 10(11), 816.

48. Yin J., Chen J. C., Wu Q., Chen G. Q. (2015), Halophiles, coming stars for industrial biotechnology. Biotechnol Adv 33 (7), 1433-1442. 